\title{
Evolution of image receptors in dental radiology
}

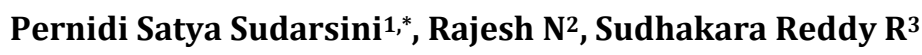 \\ ${ }^{1}$ Postgraduate student, 2 Reader, ${ }^{3}$ Professor, Department of Oral Medicine and Radiology, Vishnu Dental \\ College, Bhimavaram, West Godavari, 534202, Andhra Pradesh, India.
}

\section{N F O R M A T I O N}

\section{Article History}

Received 21 ${ }^{\text {st }}$ December 2019

Received revised $11^{\text {th }}$ January

2020

Accepted 20th January 2020

Available online

$9^{\text {th }}$ March 2020

\section{K E Y W O R D S}

Image receptors,

Conventional image receptors,

Digital image receptors

\section{A B S T R A C T}

The quality of a radiograph depicted by geometric and visual characteristics, in turn, also depends on the quality of image receptors. Image receptors in dentistry have seen an enormous evolution trend from conventional $x$-ray films to the current generation of digital image receptors. The development of cost-effective image receptors is established in various types of imaging procedures. The present article provides an insight into the evolution of various image receptors used in dental radiology.

\section{Introduction}

Image refers to a picture or reflection of an object. It is derived from the Latin word, imitate. An image is a reproduction or representation of the physical form of a person, or thing [1]. Receptor means anything that responds to a stimulus.

IMAGE RECEPTOR can be defined as a medium that changes the X-ray beam into a visible image. The absorption and scattering of photons out of the primary beam reduces a beam of x-rays photons that pass through the object. The $x$-ray film or image receptors help to record the information about the object through which $\mathrm{x}$-rays penetrate and which help to form the image [2].

Dental image receptors used today are films, screen-film combinations, the electronic sensors that are used in digital imaging, and cone-beam computed tomography [3]. Image receptors can be Conventional receptors or digital receptors. This article provides a comprehensive overview of image receptors that are used and the current evolution of the same.

\section{History of image receptors}

\subsection{History of conventional image receptors}

From the time when X-rays were discovery by Wilhelm Conrad Roentgen in 1895 , the film became the primary vehicle for capturing, displaying and storing radiographic images. Earlier in the 1900s, glass plates wrapped in the black paper were used as image receptors. With the improvement of the power supply, this photographic glass plates used as the image receptors were replaced by the films. Later the photographic cellulose film that had long been used for dental radiology replaced these plates [1]. 
Dr Otto Walkhoff took the first original dental roentgenogram exposed on a portion of a glass imaging plate in January 1896. He took it in his mouth for an exposure time of 25 minutes [4]. Since then, dental imaging has shown tremendous progression along with its varied applications in fields of dentistry.

As early as 1896, Photographic film and paper had been tried for the recording of X-ray images. In 1896, William J. Morton used roll films manufactured by Eastman Kodak Company, and in 1900, Weston A. Price designed celluloid base dental film. In 1909, Kells reported using roll-type photographic film. However, despite their weight, bulk, fragility, cost, and patient discomfort in dental radiology, glass plates continued to be used.

In 1919, machine wrapped first dental film packet called Regular film (Kodak) was marketed. This film has emulsion on one side and was relatively slow; a molar exposure required 8-9 seconds. However, it produced sharp images. Later in 1924, the emulsion was placed on both sides of the film, that doubled the speed of the film (reduced exposure to 50\%). This film was sold under the name Radiatized film (Kodak).

In 1924, the American Eastman Kodak Company turned out to be the modernizer of radiographic filming. In 1940, Ultra speed film was developed, and the speed of the film was doubled. In 1955, the speed rate of both these films was improved by a factor of 8 . In the early 1980s, Ekta speed films were developed. These speed films further reduced exposure by $50 \%$ and are currently undergoing the slow but inevitable acceptance.

Later, a new dental x-ray film Dentus M4 was announced by Agfa. Eastman Kodak Co Kodak manufactured Ekta-speed plus films in 1994. Agfa Dentus M2 Comfort film was marketed in 1997. In 2001, F-speed films were introduced. Legacy of this progression of the ever faster film has been a concomitant lesser patient exposure. While changes in the film speed accompanied, the film base was also undergoing improvements. In the early 1920s, cellulose nitrate was used, which was highly flammable and when burned, it emitted large amounts of poisonous gases. Even though invented in 1906, a non-inflammable cellulose triacetate base was not marketed till 1924. As it has a disadvantage as a film base, that is expensive subject to mould, wrinkle, tendency to break. Until 1929, when a fire in Cleveland Hospital claimed more than 100 lives, cellulose nitrate continued to be the most popular base material. Later, the cellulose nitrate was replaced with cellulose acetate. In the early 1960s, the film base of polyester (poly ester film base) was introduced and has been the material of choice. This polyester film base can be made thinner and does not tend to warp as it is stronger than cellulose acetate.

The technology used for extra-oral imaging is as old as the discovery of X-rays. Yet today, dental radiologists are still finding new ways to improve diagnostic qualities of extra-oral radiography, at the same time reducing radiation exposure levels.

\subsection{History of digital image receptors}

In 1987, the dawn of the digital era in dental radiography came when the first digital radiography system called Radio Visio Graphy, was launched by the French company Trophy Radiologie in Europe [5]. Dr Francis Mouyen was the inventor of this system. He invented a method to employ fibre optics to confine a large image of x-ray onto a smaller size that could be detected by a Charge Coupled Device image sensor chip. The new technology was ready to expand. More than two decades after this, today's digital radiographic systems have developed a great superiority and have many benefits [6,7].

\section{Classification}

Image receptors can be divided into two types such as conventional receptors and digital receptors.

\subsection{Classification of $X$-Ray Films}

There are different types of X-ray films which are classified based on various criteria, as described in table 1.

The development of cost-effective Intraoral and extraoral digital technology, together with an increase in computerization, has made digital imaging a higher alternative in many aspects to conventional film imaging. Two technologies that create digital images include direct digital images and semi-direct digital images. Direct digital images are acquired by using a solid-state sensor. These solid-state sensors are based on charge-coupled device (CCD) and complementary metal-oxide-semiconductor (CMOS).Semi-direct digital images are obtained using a phosphor plate system [8]. 


\subsubsection{Direct-action or non-screen film}

These are sometimes referred to as wrapped or packet film. This film is sensitive primarily to X-ray photons.

\subsubsection{Indirect-action or screen film}

Indirect-action or screen film, so-called because it is used with a combination of intensifying screens in a cassette. This type of film is sensitive primarily to light photons, which are emitted by the adjacent intensifying screens.The advantage of intensifying screens and the indirect-action film is that they respond to shorter exposure to X-rays, allowing a lower dose of radiation to be given to the patient. However, this is at the cost of inferior image quality [9].

\subsubsection{Intraoral films: (the $x$-ray film is inside the mouth)}

\subsubsection{Periapical Films}

Periapical films are used to record the whole tooth, from the crown to beyond the root where it attaches into the jaw. Periapical $\mathrm{x}$-rays detect any unusual changes in the root and surrounding bone structures. Film packs come in three sizes: size 0 for small children $(22 \times 35 \mathrm{~mm})$; size 1 -which is relatively Narrow and used for views of the anterior teeth $(24 \mathrm{X} 40 \mathrm{~mm})$; and size 2- the standard film size used for adults (31 X $41 \mathrm{~mm}$ ) (Figure 1).

\subsubsection{Bitewing film}

Bitewing (interproximal) films (Figure 2) are used to record the coronal portions of the maxillary and mandibular teeth in a single image. They are useful for identifying interproximal caries and evaluating the height of alveolar bone. In small children, size 0 may be used, and the smaller size 1 is preferred in children. Size 2 film normally is used in adults. In some instances, long size 3 is used in adults, which measures $53 \times 26 \mathrm{~cm}$.

\subsubsection{Occlusal film (Sandwich radiography) [10]}

Occlusal film measures about $57 \times 76 \mathrm{~cm}$ in dimension. It covers larger areas of the maxilla or mandible than may be seen in a Periapical film. The name comes from the fact that the film usually is held in position by having the patient bite lightly on it to support it between the occlusal surfaces of the teeth (Figure 3 ).

\subsubsection{Extraoral films}

These films are called screen films or indirect films as the radiographic film isplacedbetween two intensifying screens within a cassette. Screen films are employed in extraoral radiography such as orthopantamograph, lateral cephalograph, skull views, TMJ views, and lateral oblique views of the mandible [7]. Extraoral films are usually available in the following sizes;

- 6X12 inches -orthopantomography

- 8X10 inches- all other skull radiographs: PNS, PA view, lateral cephalogram, etc

- 6 X8 inches - TMJ views, lateral oblique

- $5 \times 7$ inches - This size is not often used. It may be used for transcranial films (used for TMJ views) or for lateral oblique jaw films.

\subsubsection{Duplicating film}

The duplicating Film is a type of film that is used to make an identical copy of an intraoral or extraoral radiograph. The film that is to be duplicated is placed against the emulsion side of the duplicating film, and both the films are held in position by a glass-topped cassette or photographic printing frame [2]. When the films are exposed to light, light passes through the clear areas of the original radiograph and exposes the duplicating film. The duplicating film is then processed in conventional film processing solutions. As on the original radiograph, areas exposed to light come out clearly. Duplication frequently results in obtained images with less resolution and more contrast than the original radiograph. The best images are obtained when the ultraviolet light source is used. Unlike intraoral radiograph, it is used only in a darkroom setting and not exposed to $\mathrm{x}$-ray. It does not have an orientation dot.

\subsubsection{Self Processing film}

The self-processing film is an alternative to manual processing. The film is available along with the processing solutions. The $\mathrm{x}$-ray film is presented in a single sachet containing developer and fixer (Figure 4).

\subsubsection{Speed of the films}

Film speed refers to the amount of the radiation that is required to produce an image of a standard density.

\subsubsection{Slow speed films}

The emulsion is present on one side only in the film with the small size of crystals. More exposure time is needed but better detail definition can be seen in A, B, and C speed films.

\subsubsection{Fast speed films}

The emulsion is present on both sides of the film. The 

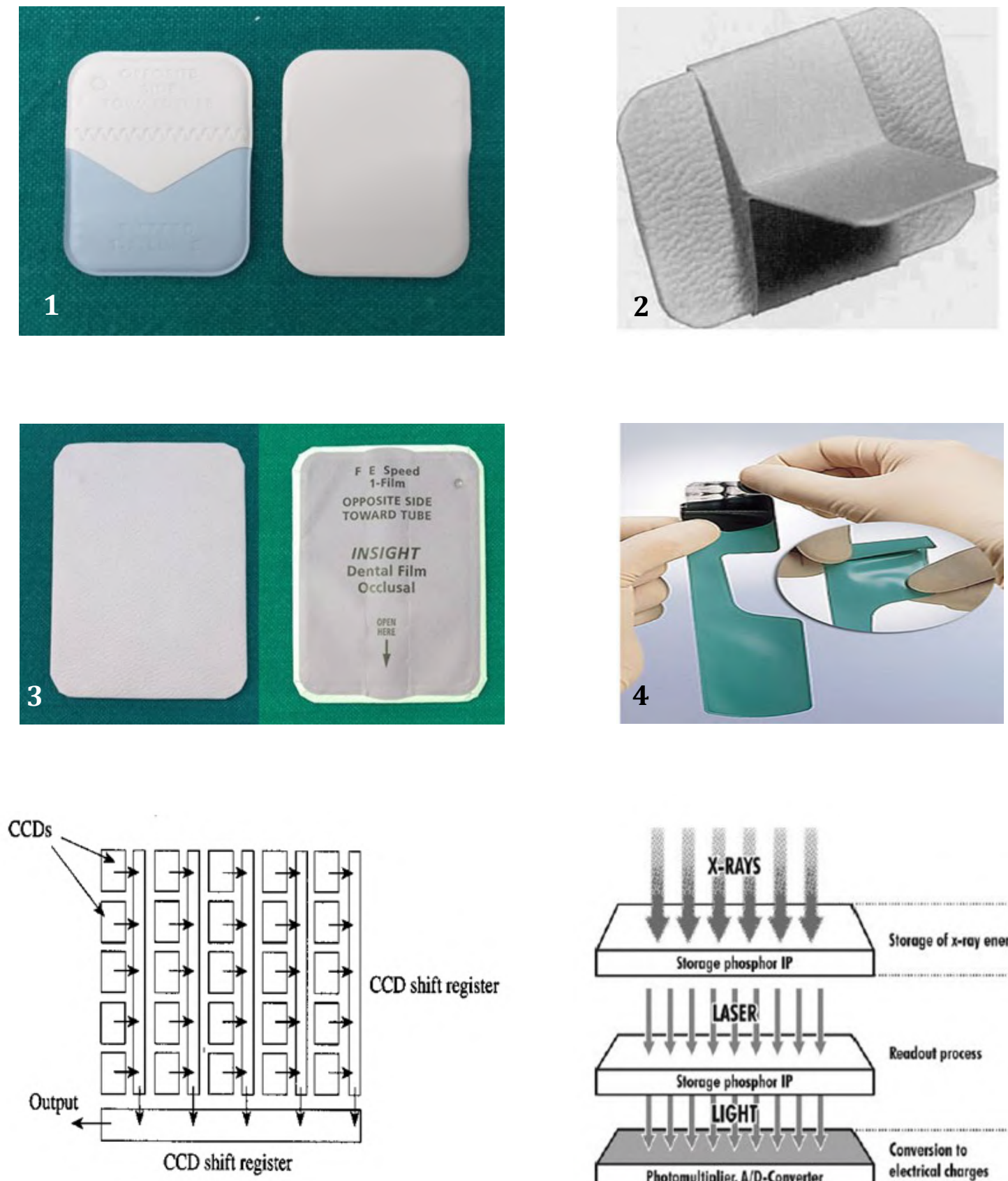

5

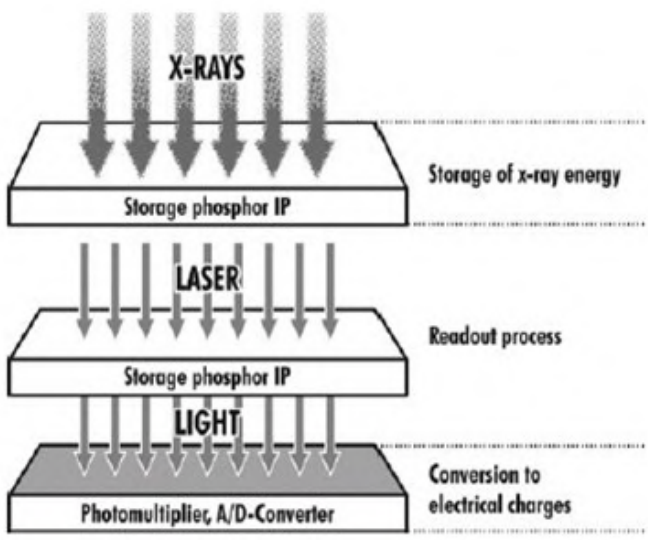

6

\section{Figures 1. Size 2 periapical film, 2. Bitewing film, 3. Occlusal radiograph, 4. Self processs- ing film, 5. Bucket Brigade Pattern, and 6: PSP image processing}

faster film has large crystals and the increased amount of silver bromide in the emulsion hence, they require less exposure radiation as seen in D-ultra speed, Eekta speed, and F-ultra ekta speed film.

\subsubsection{Hyperspeed G films}

These are 800- speed films that can halve the exposure without blurring the image.

\section{Digital image receptors}

Digital imaging is similar to film-based imaging in the interaction of $\mathrm{x}$-rays with a receptor, processing of a latent image, and in subsequent viewing of the image. In digital imaging, the image receptors are highly sensitive sensors and require considerably less radiation exposure than film. The data acquired by the receptor is analogue in the form of a continuous grayscale, and it must be converted to digital data that is to be useful. 
The ADC or analogue-to-digital converter transforms analogue information into numerical information based on the binary number system. Computers operate this binary number system in which two digits $(0$ and 1) are used to represent information or data [11]. Digital radiography receptors include "direct" and "indirect" receptors. Direct receptors communicate with the computer with the help of electronic cable or, more recently, wirelessly. Indirect receptors require a scanning step.

\subsection{Charged Coupled Device (CCD)}

The CCD was introduced to dentistry in 1987. It was the first digital image receptor to be adapted for intraoral imaging [12]. CCDs are electronic devices, which convert light into electronic charge in a silicon chip (integrated circuit). This charge is digitized and stored on a computer as an image.

A CCD contains a sensor that is placed in the patient's mouth. A cable leads from the sensor to an interface, which is connected to a computer in the operatory. After exposure, x-ray energy is transformed into a proportional number of electrons, which are deposited in the electron wells, then transferred sequentially to a read-out amplifier. This analogue signal is converted to a digital signal, and then $\mathrm{x}$-ray image is visible almost immediately on the computer monitor. The structure of CCD is a serial arrangement called "Bucket Brigade Pattern" (Figure 5). Sensors are available in different sizes such as size 0,1 , and 2 to simulate the various film sizes used clinically.

\subsection{Complementary metal-oxide-semiconductor}

Complementary metal-oxide semi-conductors are silicon-based semiconductors; these are fundamentally different from CCDs in the way that pixels are read. Electron hole pairs generated in pixels are proportional to radiation dose. Each pixel is isolated from neighbouring pixels and directly connected to the transistor. The charge here is transferred to the transistor as a small voltage. Each transistor addressed the voltage separately, read by a frame grabber, and then stored and displayed on the screen as a digital gray value. This system requires less power to operate and is less expensive to manufacture [5].

\subsection{Flat Panel Detectors}

They are commonly used in extraoral imaging devices. Two approaches have been taken in selecting $\mathrm{x}$-ray sensitive material for flat-panel detectors. Indirect

\section{Table 1: Classification of X-Ray films}

According to sensitivity

According to use

According to the speed of the film

According to packaging

According to the coating of 1 . Single coated emulsion
1. Direct action / nonscreen film

2. Indirect action/ screen film

1. Intraoral films

2. Extraoral films

3. Duplicating films

4. Self-developing film

1. Slow speed film

2. Fast speed film

3. Hyperspeed $\mathrm{G}$

1. Single film packet

2. Double film packet detectors are sensitive to visible light than $\mathrm{x}$-rays, so a layer of intensifying material (Gadolinium Oxybromide/Cesium iodide) is used to convert $x$ rays energy to light. Direct detectors use a photoconductor material selenium. On applying the electric field, the electrons that are freed during x-ray exposure of "selenium" are conducted in a direct line to underlying thin-film transistor (TFT) detectors elements. The electrical energy generated is proportional to x-ray exposure and is stored at each pixel in a "CAPACITORS." These detectors are expensive and likely to be limited to specialized imaging tasks such as cone beam imaging [2].

\subsection{Photostimulable phosphor plates (PSP)}

The Photostimulable phosphor plates (PSP) consist of a flexible polyester base with a coated crystalline emulsion of the "europium doped barium fluorohalide" compound. In order to control the infection, the plate is placed in a plastic pouch and sealed to prevent contact with oral fluids. After exposure, x-ray energy is stored in the emulsion and a latent image forms on the PSP plate, similar to the latent image that forms on a conventional emulsion. Next, the plate is placed into a laser scanner, which acts as an electronic processor. A laser beam serially scans the plate, and the stored electrons are released as visible light, which is quantified. The obtained analog signal is converted to a digital image, which is viewed on a computer screen (Figure 6). Because all the energy stored on the PSP plate is not released during scanning, it must be "erased" by exposing the plate to a strong source of light for 
seconds before it is reused. PSP plates are available in similar sizes of intraoral films, as well as larger sizes for extraoral imaging [13].

\subsection{Comparison of properties of image recep- tors}

The time comparison for the acquisition of image is CCD $<$ PSP = Film. Most conventional E speed films have a resolution of 20 Line pairs $/ \mathrm{mm}$, whereas with digital images have the resolution ranges from 7-10 Line Pairs $/ \mathrm{mm}$. The comparison of image resolution for various systems such as for Intraoral systemsFilm > CCD > PSP; Panoramic systems- Film = CCD = PSP; and for Cephalometric systems: Film > CCD = PSP [2].

\section{Conclusion}

In this current era of dental imaging, Digital imaging has garnered enormous recognition for its costeffective property and also in terms of quality. Though the Digital image receptors have advantages of improved visual characteristics, the conventional image receptors have their advantage of image resolution. The judicious use of these receptors always embraces the image quality and thereby providing an accurate diagnosis.

Conflicts of interest: Authors declared no conflicts of interest.

Financial support: None

\section{References}

1. Tim Peter. Image Receptors: An update. Int J Innovation AppStud. 2014;7(1):205-212.

2. White SC, Pharoah MJ. Oral radiology principles and interpretation. 6th ed. St Louis; Mosby: 2009.

3. Stabulas-Savage. Radiology for the dental professional. 9th Edition by Frommer.

4. Shah N, Bansal N, Logani A. Recent advances in imaging technologies in dentistry. World J Radiol. 2014;6:794-807.

5. Parks ET, Williamson GF. Digital radiography: an overview. J Contemp dent Pract.2002;3:1-13.

6. Vander Stelt PF. Filmless imaging: The uses of digital radiography in dental practice. J Am Dent Assoc 2005;136:1379-1387.
7. Duvvaru LSR, Jain V, Mittal S, Alla RK. The Shadow Capturers that Revolutionised Radiology:Image Receptors. Trends Biomater Artif Organs. 2018; 32 (3):128-132.

8. Williamson GF. Digital radiography in dentistry: moving from film? based to digital imaging (internet). 2014 [updated 2014 Feb 14]. Available at: http://www.dentalcare.com/media/ en? US/ education/ce350/ce350.pdf. Accessed June 12, 2015.

9. Eric whaites. Essentials of dental radiography and radiology. 4th edition.

10. Freny RKarjodkar. Essentials Of oral \& maxillofacial radiology, 2 nd edition.

11. Van der Stelt PF. Principles of digital imaging. Dent Clin North Am. 2000;44(2):237-48.

12. Dhir P, David C, Keerthi G, Sharma V, Girdhar V. Digital imaging in dentistry: an overview. Int J Med Dent Sci. 2014;3(2):524.

13. Petrikowski CG. Introducing digital radiography in the dental office: an overview. J Can Dent Assoc 2005; 71(9):651-651. 